\title{
CHEMOTHERAPY-INDUCED FATIGUE INDUCES A SPECIFIC GENE EXPRESSION PROFILE IN PERIPHERAL BLOOD MONONUCLEAR CELLS OF BREAST CANCER PATIENTS RECEIVING ADJUVANT OR NEOADJUVANT CHEMOTHERAPY
}

Barbara B. R. Alcântara1 ${ }^{1}$, Felipe M. Cruz ${ }^{1}$, Fernando L. A. Fonseca ${ }^{1,2}$, Beatriz C. A. Alves ${ }^{1}$, Matheus M. Perez ${ }^{1}$, Patricia Varela ${ }^{3}$ João Bosco Pesquero $^{3}$, Daniel I. G. Cubero ${ }^{1,4}$, Claudia V. M. Sette ${ }^{5}$, Auro Del Giglio ${ }^{1}$

${ }^{1}$ ABC Foundation School of Medicine, Santo André, SP, Brazil; ${ }^{2}$ Institute of Pharmaceutical Sciences, Universidade Federal de São Paulo, Diadema, SP, Brazil; ${ }^{3}$ Center for Research and Molecular Diagnosis of Genetic Diseases, Department of Biophysics-Escola Paulista de Medicina, Universidade Federal de São Paulo, São Paulo, Brazil; Centro de Oncologia do ABC, Santo André, SP, SP, Brazil; ${ }^{5}$ Hospital Anchieta, São Bernardo do Campo, SP, Brazil.

\section{INTRODUCTION}

Chemotherapy induced fatigue (CIF) is a frequent and potentially debilitating side effect of chemotherapy that affects approximately $40 \%$ of patients and is severe in approximately onefourth of those affected. ${ }^{1}$ In addition to anemia, chemotherapy may induce fatigue through several mechanisms, including stimulation of the inflammatory response mediated by changes in cytokine levels, hormonal deregulation, or muscular toxicity. ${ }^{2-3}$.

In this work, we aimed to evaluate whether CIF can induce a specific gene expression profile in peripheral blood mononuclear cells (PBMNC) of patients with locoregional breast

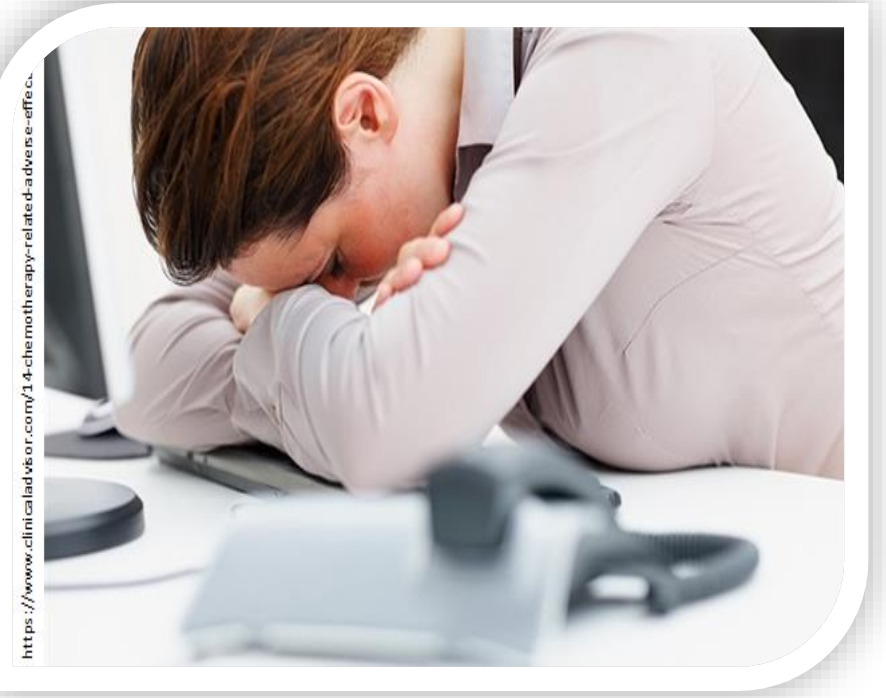
cancer (LRBC) who are receiving chemotherapy through RNA-seq analysis.

\section{METHODS WORKFLOW}

BLOOD CELLS

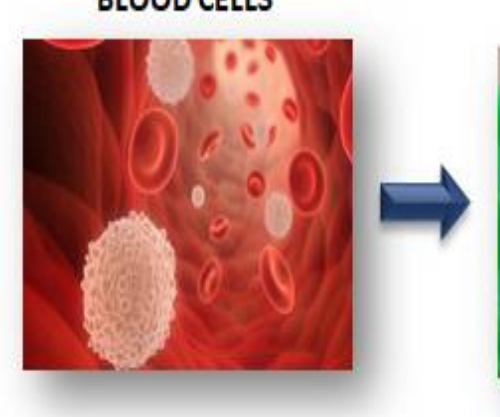

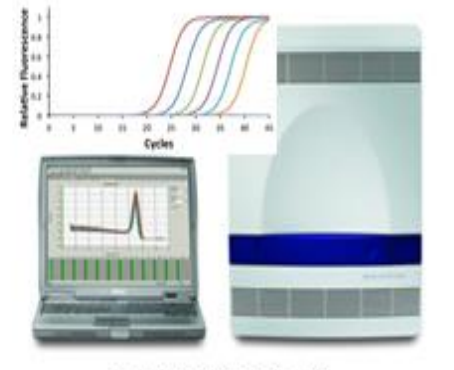

qPCR VALIDATION
RNA ISOLATION
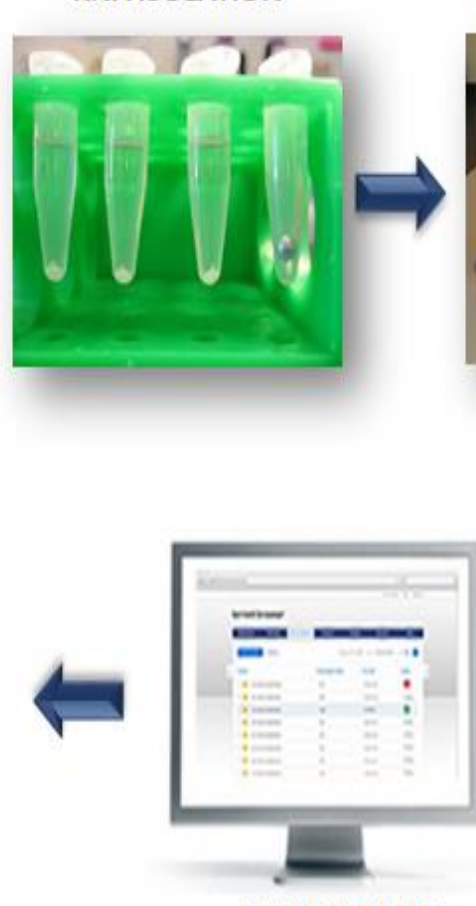

DATA ANALYSIS
RIN DETERMINATION

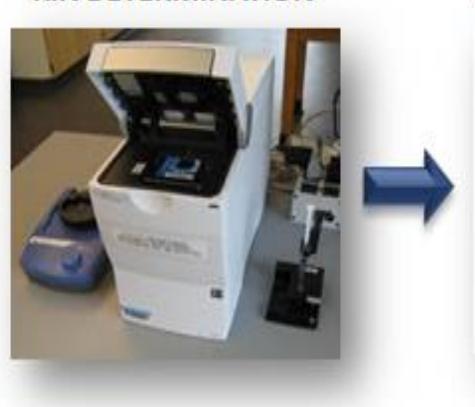

IBRARY CONSTRUCTION
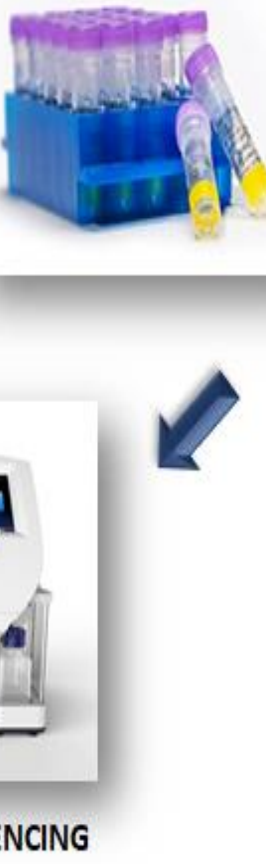

RESULTS

A total of 12.345 transcripts were sequenced, of which 26 were selected out of 71 that had significantly different expression before and after chemotherapy. These 26 genes as well as their expression fold change obtained by RNA-seq and validated by GPCR can be found in Table 1 . We observed a significant increase in expression of DUSP18 and RHOBTB1 and decreased expression of NCAN and RAET1G in patients who developed CIF after chemotherapy. Control patients only exhibited a significant decrease in NCAN expression.

\section{CONCLUSION}

CIF induces specific changes in gene expression in the PBMNC of LRBC patients. Some of these changes, such as down-regulation of NCAN expression, may reflect direct effects of chemotherapy since they are also observed in the controls. Furthermore, CIF may involve down-regulation of skeletal muscle genes (RHOBT1, DUSP18) and immune systems (RAETG1), whereas NCAN downregulation may underlie the adverse cognitive effects of chemotherapy.

\section{REFERENCES}

1) Gilliam LA, St Clair DK (2011) Chemotherapy-induced weakness and fatigue in skeletal muscle: the role of oxidative stress. Antioxid Redox Signal 15:254-2563.

2) Bower JE (2014) Cancer-related fatigue-mechanisms, risk factors, and treatments. Nat Rev Clin Oncol 11:597-609.

3) Saligan LN, Olson K, Filler K, Larkin D, Cramp F, Sriram Y, Escalante CP, Del Giglio A, Kober KM, Kamath J, Palesh O, Mustian K and Multinational Association of Supportive Care in Cancer Fatigue Study Group Biomarker Working Group (2015) The biology of cancer-related fatigue: a review of the literature. Support Care Cancer 23:2461-2478.

\section{PATIENTS AND METHODS}

Patients with stage I, II and III breast cancer undergoing adjuvant systemic chemotherapy based on the use of anthracyclines were screened before the start of their treatment. We assessed $\mathrm{CIF}$ according the $\mathrm{BFI}$ and Chalder Questionnaires. Total RNA was isolated from blood samples. RNA-seq was performed in an Ion Torrent $^{\text {TM }}$ System. The RNA-seq results were validated by RT-qPCR in a different group of 28 patients with LRBC who developed CIF after their first cycle of chemotherapy and in 06 patients who also received chemotherapy but did not develop CIF (controls).

Table 1. Genes differentially expressed in CIF

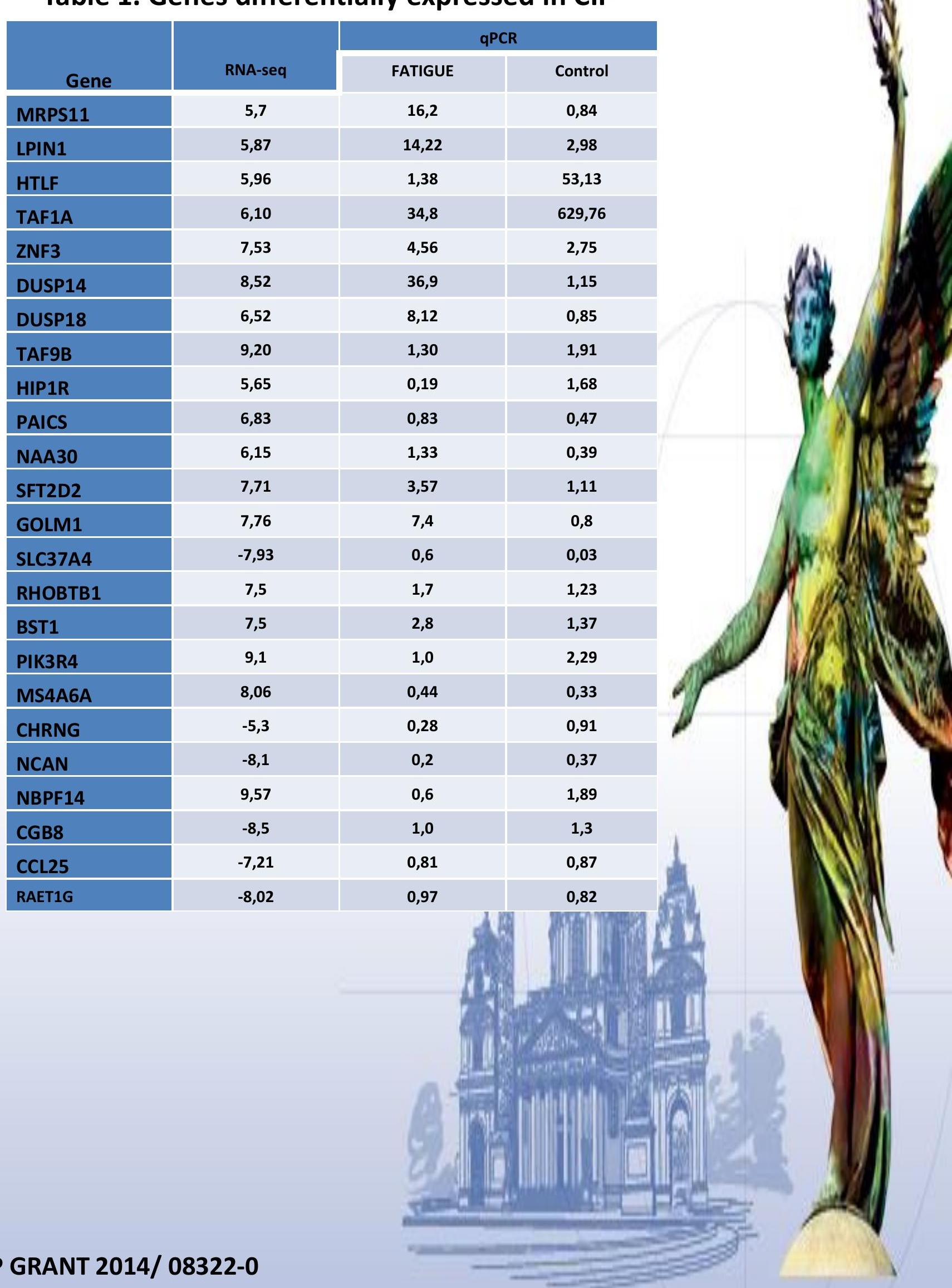

